\title{
Association Between Distance From Home to Tobacco Outlet and Smoking Cessation and Relapse
}

\section{Citation}

Pulakka, Anna, Jaana I. Halonen, Ichiro Kawachi, Jaana Pentti, Sari Stenholm, Markus Jokela, Ilkka Kaate, Markku Koskenvuo, Jussi Vahtera, and Mika Kivimäki. 2016. "Association Between Distance From Home to Tobacco Outlet and Smoking Cessation and Relapse." JAMA Internal Medicine 176 (10): 1512. https://doi.org/10.1001/jamainternmed.2016.4535.

\section{Permanent link}

http://nrs.harvard.edu/urn-3:HUL.InstRepos:41275594

\section{Terms of Use}

This article was downloaded from Harvard University's DASH repository, WARNING: This file should NOT have been available for downloading from Harvard University's DASH repository.

\section{Share Your Story}

The Harvard community has made this article openly available.

Please share how this access benefits you. Submit a story.

Accessibility 


\section{Association Between Distance From Home to Tobacco Outlet and Smoking Cessation and Relapse}

Anna Pulakka, PhD; Jaana I. Halonen, PhD; Ichiro Kawachi, MD, PhD; Jaana Pentti, BSc; Sari Stenholm, PhD; Markus Jokela, PhD; Ilkka Kaate, MSc; Markku Koskenvuo, MD, PhD; Jussi Vahtera, MD, PhD; Mika Kivimäki, PhD

IMPORTANCE Reduced availability of tobacco outlets is hypothesized to reduce smoking, but longitudinal evidence on this issue is scarce.

OBJECTIVE To examine whether changes in distance from home to tobacco outlet are associated with changes in smoking behaviors.

DESIGN, SETTING, AND PARTICIPANTS The data from 2 prospective cohort studies included geocoded residential addresses, addresses of tobacco outlets, and responses to smoking surveys in 2008 and 2012 (the Finnish Public Sector [FPS] study, $n=53$ 755) or 2003 and 2012 (the Health and Social Support [HeSSup] study, $n$ = 11924). All participants were smokers or ex-smokers at baseline. We used logistic regression in between-individual analyses and conditional logistic regression in case-crossover design analyses to examine change in walking distance from home to the nearest tobacco outlet as a predictor of quitting smoking in smokers and smoking relapse in ex-smokers. Study-specific estimates were pooled using fixed-effect meta-analysis.

EXPOSURES Walking distance from home to the nearest tobacco outlet.

MAIN OUTCOMES AND MEASURES Quitting smoking and smoking relapse as indicated by self-reported current and previous smoking at baseline and follow-up.

RESULTS Overall, 20729 men and women (age range 18-75 years) were recruited. Of the 6259 and 2090 baseline current smokers, 1744 (28\%) and 818 (39\%) quit, and of the 8959 and 3421 baseline ex-smokers, 617 (7\%) and 205 (6\%) relapsed in the FPS and HeSSup studies, respectively. Among the baseline smokers, a 500-m increase in distance from home to the nearest tobacco outlet was associated with a $16 \%$ increase in odds of quitting smoking in the between-individual analysis (pooled odds ratio, 1.16; $95 \% \mathrm{Cl}, 1.05-1.28$ ) and 57\% increase in within-individual analysis (pooled odds ratio, 1.57; 95\% Cl, 1.32-1.86), after adjusting for changes in self-reported marital and working status, substantial worsening of financial situation, illness in the family, and own health status. Increase in distance to the nearest tobacco outlet was not associated with smoking relapse among the ex-smokers.

CONCLUSIONS AND RELEVANCE These data suggest that increase in distance from home to the nearest tobacco outlet may increase quitting among smokers. No effect of change in distance on relapse in ex-smokers was observed.

JAMA Intern Med. 2016;176(10):1512-1519. doi:10.1001/jamainternmed.2016.4535 Published online August 15, 2016

\author{
Invited Commentary \\ page 1520 \\ Supplemental content at \\ jamainternalmedicine.com
}

Author Affiliations: Author affiliations are listed at the end of this article.

Corresponding Author: Anna Pulakka, PhD, Department of Public Health, University of Turku, Joukahaisenkatu 3-5, 20014 Turku, Finland (anna.pulakka@utu.fi). 
S moking continues to be a leading health risk globally, ${ }^{1,2}$ emphasizing the need for identifying measures to curb the tobacco epidemic. ${ }^{3}$ Tobacco retail outlets in residential environment received increasing attention as potential targets for policies to reduce smoking. ${ }^{4,5}$ However, there is currently insufficient evidence to demonstrate a causal association between tobacco retail environment and smoking behaviors.

Easier residential access to cigarettes is associated with higher likelihood of smoking in cross-sectional studies. ${ }^{6-10}$ However, cross-sectional data do not provide a secure basis to infer causality. In the few longitudinal studies addressing this question, the findings have been inconsistent. ${ }^{11-14}$ Depending on the study, proximity of residence to tobacco outlets has predicted smoking behaviors in high poverty areas but not in affluent areas, ${ }^{13}$ in men but not in women, ${ }^{14}$ and when using proximity but not density-based indicators of access. ${ }^{11}$ Some studies have failed to show any association with smoking behavior. ${ }^{12}$ Importantly, none of the existing prospective studies have been informative about the effect of a change in access to tobacco on changes in smoking behaviors-a key issue for policy.

To address some of these limitations, we linked repeated assessments of self-reported smoking behaviors to repeated data on the walking distance from home to the closest tobacco outlet using geocoded data. For comparison, we also assessed the number of tobacco outlets close to home, a densitybased measure. Our aim was to examine whether change in proximity of tobacco stores in the residential neighborhood was associated with quitting smoking or smoking relapse.

\section{Methods}

\section{Study Setting and Population}

The data were drawn from 2 prospective cohort studies: the Finnish Public Sector (FPS) study and the Health and Social Support (HeSSup) study. The FPS included employees representing a wide range of occupations working in 10 towns and 6 hospital districts; they responded to 2 identifiable postal surveys in 2008 (baseline) and 2012 (follow-up) (2009 and 2013, respectively, if they had retired or left the organizations). ${ }^{14}$ HeSSup targeted a sample representative of the Finnish population in 4 age groups (20-24, 30-34, 40-44, and 50-54 years) in $1998 .{ }^{15}$ For the present analysis of HeSSup, the baseline survey was sent in 2003 and the follow-up in 2012. The FPS was approved by the ethics committee of the Hospital District of Helsinki and Uusimaa and HeSSup by the joint ethics committee of the University of Turku and the Turku University Central Hospital.

Figure 1 presents the selection of the analytic sample. We included the FPS participants who responded to the survey both in 2008 or 2009 and 2012 or 2013 ( $n=53755,79 \%$ of the eligible 2008/2009 respondents) and the HeSSup participants who responded both in 2003 and 2012 ( $n=11924,63 \%$ of the eligible 2003 participants). We focused on current and ex-smokers only and excluded those who reported never smoking at baseline. In addition, we excluded those with missing

\section{Key Points}

Question Is change in proximity of tobacco outlets in residential neighborhoods associated with quitting smoking or smoking relapse?

Finding In 2 independent longitudinal cohorts of smokers, each 500-m increase in distance from home to the nearest tobacco outlet was associated with a $20 \%$ to $60 \%$ increase in odds of quitting smoking. Increase in distance to tobacco outlet was not associated with the odds of smoking relapse among ex-smokers.

Meaning Reducing tobacco outlets in residential areas could contribute toward curbing tobacco consumption, a leading cause of morbidity and mortality.

data on smoking in either survey, not residing in mainland Finland, or with unsuccessful geocoding of residential address. The analytic sample was therefore 15218 FPS and 5511 HeSSup participants.

\section{Assessment of the Distance From Home to Tobacco Outlets} The residential address coordinates were derived from Population Register Centre at the time of the baseline (FPS, 2008/2009; HeSSup, 2003) and follow-up (FPS, 2012/2013; HeSSup, year 2012) surveys, a data linkage which was successful for all participants. During the follow-up, 5464 FPS participants (36\%) and 2552 of HeSSup participants (44\%) changed their residential address.

Tobacco retail has been subject to licensing in Finland since April 2009 (eMethods in the Supplement). ${ }^{16}$ We obtained all the addresses of outlets with a tobacco retail license effective in 2010 (baseline) and 2013 (follow-up) from the National Supervisory Authority for Welfare and Health. A geocoding service, together with the researchers, geocoded the outlet addresses into EUREF-FIN coordinates using ArcGIS 10.2.2 software (Esri Inc). This geocoding was successful for 8166 outlets (92\%) from 2010 and 8286 outlets (96\%) from 2013.

In both cohorts, we determined walking distance from the (1) residential address coordinates at baseline to the 2010 tobacco outlet coordinates and (2) from the residential address coordinates at follow-up to the 2013 tobacco outlet coordinates. Using the 2013 road and street database (Esri Finland Oy), that includes all roads, streets, and sidewalks ${ }^{17}$ as a basemap, we used the Network Analyst tool in ArcGIS to find the nearest tobacco outlet. As the baseline smoking was measured earlier (2003) than the baseline tobacco outlet coordinates (2010) in the HeSSup study, we performed a sensitivity analysis excluding participants with likely unmeasured change in distance to tobacco outlet between 2003 and 2010 (eMethods in the Supplement). This had little effect on the findings (eTable 1 in the Supplement), suggesting that the time discrepancy in baseline smoking behavior and tobacco outlets in HeSSup was an unlikely source of major bias.

We used the difference between baseline and follow-up distance to determine change in walking distance from home to the nearest tobacco outlet. The median distance at baseline was $528 \mathrm{~m}$. To take into account variation in the walking distance only, we set all distances above $1000 \mathrm{~m}$ to $1000 \mathrm{~m}$ as few people 


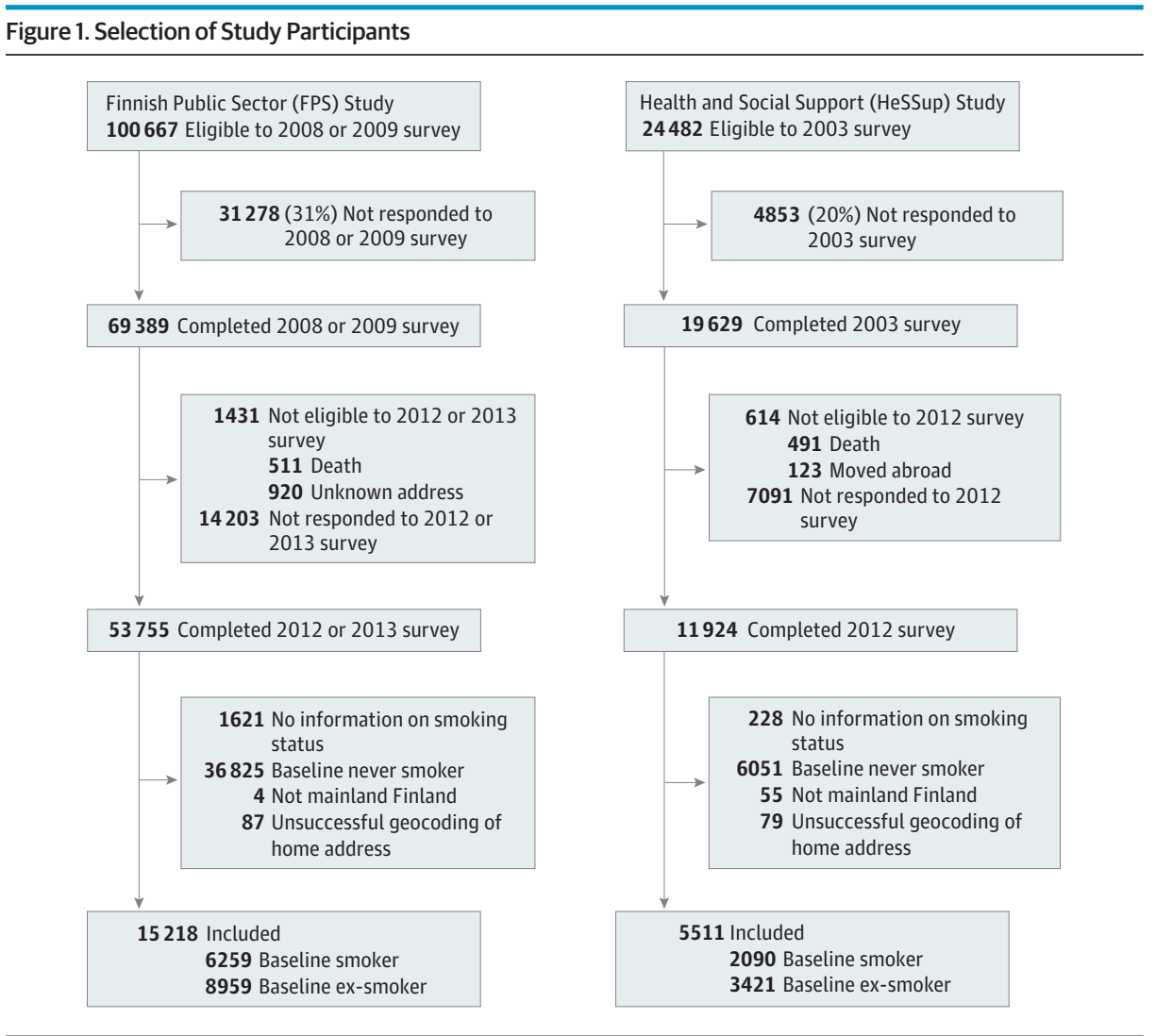

Finnish Public Sector (FPS) participants who responded to the survey both in 2008 or 2009 and 2012 or 2013 ( $n=53755,79 \%$ of the eligible 2008/2009 respondents) and the Health and Social Support (HeSSup) participants who responded both in 2003 and 2012 ( $n=11924,63 \%$ of the eligible 2003 participants) were included. Current and ex-smokers were included only and those who reported never smoking at baseline were excluded. In addition, those with missing data on smoking in either survey, not residing in mainland Finland, or with unsuccessful geocoding of residential address were excluded. The analytic sample was therefore 15218 FPS and 5511 HeSSup participants. are likely to travel further away by foot. The results were similar when using a formula that follows Gaussian dispersion: $\exp \left[-6(\text { distance })^{1.2}\right]^{14,18}$ to quantify the distance (without setting restrictions) from home to the nearest tobacco outlet (eTable 2 in the Supplement). As a density-based measure, we calculated the number of outlets within $500 \mathrm{~m}$ (by straight-line distance) from home ( $0,1,2$ or more) at baseline and follow-up, and used the difference to measure change in availability. ${ }^{14}$

\section{Assessment of Smoking Behavior}

In all the surveys, smoking status was measured by asking the participants "Do you smoke or have you previously smoked regularly, that is daily or nearly daily?" and "Do you still smoke regularly?". Those who responded "yes" to the second question were defined as baseline smokers while those who responded "yes" to the first and "no" to the second question were defined as ex-smokers. Those who responded "no" to both of the questions were defined as baseline never smokers. Initiation of smoking in adulthood was rare in both cohorts: only $1 \%$ of the FPS participants (370 of 36625 ) and $0.4 \%$ of the HeSSup participants (25 of 5999) never smokers started smoking during the follow-up. Consequently, we only focused on quitting smoking and smoking relapse.

\section{Covariates}

Time-invariant covariates, sex and education, were derived from the employers' registers and Statistics Finland in FPS and from the baseline survey in HeSSup. Education was used as an indicator of socioeconomic status and was categorized as low (vocational school) or high (college or higher). Age, marital status, employment (working or not), substantial worsening of one's financial situation in past year, death or severe illness in the family in past year, and chronic diseases (angina pectoris or myocardial infarction, cerebrovascular disease, diabetes, cancer, asthma and chronic bronchitis) were selfreported in the surveys and were treated as time-dependent covariates because they may potentially influence smoking behavior ${ }^{19}$ and lead to moving residence. ${ }^{20}$

\section{Statistical Analyses}

We used logistic regression (the LOGISTIC procedure in SAS) to assess the likelihood of quitting in baseline smokers and smoking relapse in baseline ex-smokers. The odds ratios (OR) and their $95 \% \mathrm{CI}$ were estimated for a 500 -m increase in walking distance to the nearest tobacco outlet, and, in the subsidiary analysis, by change in the number of tobacco outlets within $500 \mathrm{~m}$ from home. We constructed 2 models: Model 1 was adjusted for age and education at baseline; Model 2 was additionally adjusted both for baseline and follow-up information on marital status, employment, chronic diseases, worsening of financial situation in past year and recent death or severe illness in the family in past year.

As the above analyses were based on between-individual comparisons, we further examined the observed associations in within-individual analyses using conditional logistic regression in a case-crossover design. ${ }^{21-24}$ This design enables data from longitudinal cohort studies to be used in a casecontrol design where each individual serves as his or her "case" 


\begin{tabular}{|c|c|c|c|}
\hline \multirow[b]{2}{*}{ Study Variable } & \multicolumn{3}{|l|}{ No. (\%) } \\
\hline & Baseline & Follow-Up & Missing $^{\mathrm{a}}$ \\
\hline \multicolumn{4}{|l|}{ Finnish Public Sector Study ( $n=15218)$} \\
\hline \multicolumn{4}{|l|}{ Time-invariant } \\
\hline Male participant & $3663(24)$ & NA & 0 \\
\hline \multicolumn{4}{|l|}{ Education } \\
\hline Vocational school & $5178(34)$ & NA & $807(5)$ \\
\hline College degree or higher & $9233(61)$ & NA & \\
\hline \multicolumn{4}{|l|}{ Time-variant } \\
\hline Smoker & $6259(41)$ & $5132(34)$ & 0 \\
\hline Ex-smoker & 8959 (59) & $10086(66)$ & 0 \\
\hline Married/cohabiting & $10987(72)$ & $10872(71)$ & $210(1)$ \\
\hline Working full-time & $13275(87)$ & $12030(79)$ & $41(0.3)$ \\
\hline Chronic disease & $3570(23)$ & $4720(31)$ & $248(2)$ \\
\hline Worsening of financial situation & $835(5)$ & $973(6)$ & $557(4)$ \\
\hline Death or severe illness in the family & $471(3)$ & $514(4)$ & $400(3)$ \\
\hline $\begin{array}{l}\text { Distance to nearest tobacco outlet, } \\
\text { median (IQR) in } \mathrm{m}\end{array}$ & $517(265-978)$ & $534(270-981)$ & 0 \\
\hline \multicolumn{4}{|l|}{ No. of outlets within $500 \mathrm{~m}$} \\
\hline 0 & $5671(37)$ & $5869(39)$ & \\
\hline 1 & $2950(19)$ & $2866(19)$ & 0 \\
\hline$\geq 2$ & $6597(43)$ & $6483(43)$ & \\
\hline \multicolumn{4}{|l|}{ Health and Social Support Study $(n=5511)$} \\
\hline \multicolumn{4}{|c|}{ Time-invariant } \\
\hline Male participant & $2403(44)$ & NA & 0 \\
\hline \multicolumn{4}{|l|}{ Education } \\
\hline Vocational school & $2669(48)$ & NA & $24(0.4)$ \\
\hline College degree or higher & $2818(51)$ & NA & \\
\hline \multicolumn{4}{|l|}{ Time-variant } \\
\hline Smokers & $2090(38)$ & $1477(27)$ & 0 \\
\hline Ex-smokers & $3421(62)$ & $4034(73)$ & 0 \\
\hline Married/co-habiting & $4119(75)$ & $4070(74)$ & $54(1)$ \\
\hline Working full-time & $4027(73)$ & $3135(57)$ & $105(2)$ \\
\hline Chronic disease & $1279(23)$ & $1761(32)$ & $76(1)$ \\
\hline Worsening of financial situation & $365(7)$ & $323(6)$ & $735(13)$ \\
\hline Death or severe illness in the family & $231(4)$ & $605(11)$ & $782(14)$ \\
\hline $\begin{array}{l}\text { Distance to nearest tobacco outlet, } \\
\text { median (IQR) in } \mathrm{m}\end{array}$ & $563(268-1254)$ & $636(302-1383)$ & 0 \\
\hline \multicolumn{4}{|l|}{ No. of outlets within $500 \mathrm{~m}$} \\
\hline 0 & $2335(42)$ & $2572(47)$ & \\
\hline 1 & $980(18)$ & $917(17)$ & 0 \\
\hline$\geq 2$ & $2196(40)$ & $2022(37)$ & \\
\hline
\end{tabular}

Abbreviations: IQR, interquartile range; NA, not applicable.

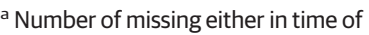
baseline or follow-up. (smoker) and "control" (ex-smoker). ${ }^{18,21,23,24}$ According to the requirements of the case-crossover approach, only those participants who reported a change in smoking status could be included in the analysis. We constructed 2 models to assess the association between change in walking distance to tobacco outlet and quitting smoking. Model 1 was, by design, adjusted for all time-invariant variables. Model 2 was further adjusted for changes in individual-level time-varying covariates: marital status, work status, chronic diseases, worsening of financial situation in past year, and death or severe illness in the family in past year.

We pooled the results of the cohort-specific analyses using fixed-effect meta-analysis to produce averaged ORs across the FPS and HeSSup studies, weighing the cohort-specific ORs by the inverse of their standard errors. Subgroup analyses were stratified by sex. ${ }^{1}$ All the cohort-specific analyses were performed using SAS 9.4 statistical software (SAS Institute Inc). For meta-analysis, we used the metan package of Stata 13.1 (StataCorp).

\section{Results}

Characteristics of the study population are shown in Table 1. Of the 6259 and 2090 baseline current smokers, 1744 (28\%) and 818 (39\%) quit, and of the 8959 and 3421 baseline exsmokers, 617 (7\%) and 205 (6\%) relapsed in FPS and HeSSup, respectively. At baseline, the mean (SD) age was 48.8 (11; range, 


\begin{tabular}{|c|c|c|c|c|c|c|c|c|}
\hline \multirow[b]{2}{*}{ Cohort } & \multicolumn{4}{|l|}{ Model $1^{\text {b }}$} & \multicolumn{4}{|l|}{ Model $2^{b}$} \\
\hline & No. (Total) & No. (Cases) & OR $(95 \% \mathrm{Cl})$ & $P$ Value & No. (Total) & No. (Cases) & OR $(95 \% \mathrm{Cl})$ & $P$ Value \\
\hline \multicolumn{9}{|c|}{ Quitting smoking among baseline smokers } \\
\hline FPS & 5953 & 1649 & $1.20(1.06-1.35)$ & .003 & 5486 & 1528 & $1.15(1.01-1.30)$ & .03 \\
\hline HeSSup & 2084 & 817 & $1.25(1.08-1.45)$ & .003 & 1631 & 647 & $1.17(0.99-1.38)$ & .06 \\
\hline Pooled & 8037 & 2466 & $1.22(1.11-1.34)$ & $<.001$ & 7117 & 2175 & $1.16(1.05-1.28)$ & .004 \\
\hline \multicolumn{9}{|c|}{ Smoking relapse among baseline ex-smokers } \\
\hline FPS & 8458 & 584 & $1.01(0.84-1.20)$ & .95 & 7895 & 549 & $1.06(0.88-1.27)$ & .57 \\
\hline HeSSup & 3403 & 205 & $1.09(0.86-1.39)$ & .47 & 2713 & 171 & $1.04(0.80-1.35)$ & .79 \\
\hline Pooled & 11861 & 789 & $1.04(0.90-1.20)$ & .61 & 10608 & 720 & $1.05(0.91-1.22)$ & .50 \\
\hline $\begin{array}{l}\text { Abbreviatior } \\
\text { Social Suppc } \\
\text { a Odds ratio } \\
\text { Maximum }\end{array}$ & $\begin{array}{l}\text { S, the Finnisł } \\
\text { Idy; OR, odds } \\
\% \mathrm{Cl} \text { ) are per } \\
\text { for distance i }\end{array}$ & $\begin{array}{l}\text { blic Sector stuc } \\
\text { o. } \\
\text {-m increase frc } \\
\text { at } 1000 \mathrm{~m} \text {. }\end{array}$ & $\begin{array}{l}\text { eSSup, the Health a } \\
\text { aseline distance. }\end{array}$ & \multicolumn{5}{|c|}{$\begin{array}{l}\text { b } \text { Model } 1 \text { is adjusted for age and education at baseline, Model } 2 \text { is adjusted } \\
\text { additionally for marital status, work status, chronic diseases, worsening of } \\
\text { financial situation and death or severe illness in the family in the past year, at } \\
\text { baseline and at follow-up. }\end{array}$} \\
\hline
\end{tabular}

Figure 2. Odds of Quitting Smoking in Relation to Increasing Distance From Home to the Nearest Tobacco Outlet

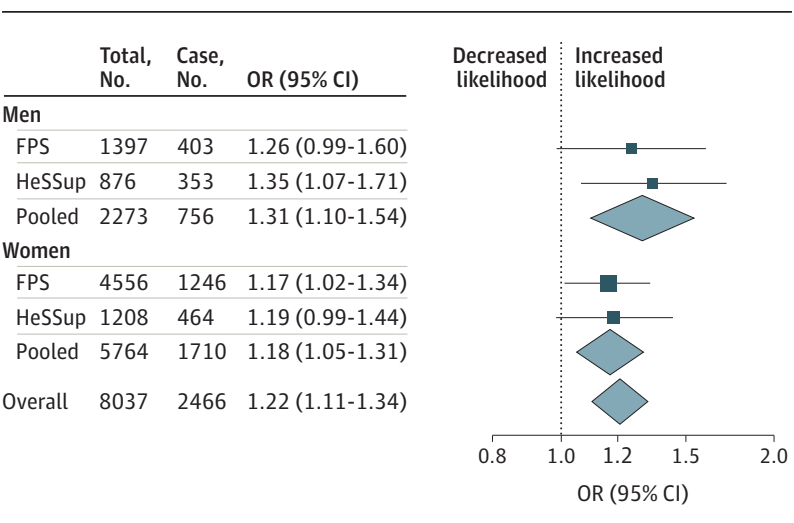

Values are odds ratios $(95 \% \mathrm{Cl})$ per 500 -m increase in distance to the nearest tobacco outlet between baseline and follow-up presented separately for the FPS and the HeSSup studies, with pooled results marked as diamond. Maximum value for distance is set at $1000 \mathrm{~m}$. Odds ratios are adjusted for age and education at baseline. FPS indicates the Finnish Public Sector study; HeSSup, the Health and Social Support study; OR, odds ratio.

18-75) years in the 15218 FPS participants and 44.7 (11; range, 25-59) years in the 5511 HeSSup participants. Median (interquartile range [IQR]) walking distance from home to the nearest tobacco outlet for the combined sample was 528 (2661041) $\mathrm{m}$ at baseline. Distance to the nearest outlet changed in $39 \%$ of the participants (median change, $242 \mathrm{~m}$; range, -997-997 $\mathrm{m}$ ).

Among the baseline smokers, the adjusted odds for quitting smoking by the follow-up was 1.22 (95\% CI, 1.11-1.34) for a 500-m increase in the distance to the nearest tobacco outlet (Table 2; pooled analysis). This association was robust to all adjustments, and it was observed in both cohort-specific analyses (Table 2) and in men and women (Figure 2). In addition, the alternative density-based measure (ie, the number of tobacco outlets within $500 \mathrm{~m}$ from home) was also associated with quitting, but only among the FPS participants: quitting smoking was more likely when the number of stores decreased (adjusted OR, 1.28; 95\% CI, 1.06-1.54) (eTable 3 in the Supplement).
Among the baseline ex-smokers, increase in the distance to a tobacco outlet was not significantly associated with smoking relapse (Table 2). This null finding was observed in cohortspecific as well as pooled analyses and was little affected by adjustments for covariates. The findings for the number of tobacco outlets within $500 \mathrm{~m}$ and smoking relapse were inconsistent (eTable 3 in the Supplement).

The results from the case-crossover design are presented in Table 3 and eTable 4 in the Supplement. The withinindividual odds for quitting smoking per 500-m increase in distance to a tobacco outlet was 1.69 (95\% CI, 1.45-1.97) in the pooled analysis. The odds were similar and significantly elevated among both men and women and in the studyspecific analyses (Table 3 ). The findings were also robust to adjustments for covariates. The alternative exposure, the number of tobacco outlets, was also associated with quitting. The adjusted OR for quitting smoking was 0.63 (95\% CI, 0.46-0.86) and 0.48 (95\% CI, 0.31-0.74) in FPS and HeSSup, respectively, when having more than 2 tobacco outlets within $500 \mathrm{~m}$ from home compared with none (eTable 4 in the Supplement).

\section{Discussion}

In this pooled analysis of 2 prospective cohorts of adults, participants were more likely to quit smoking when distance from home to the nearest tobacco outlet increased. This finding was robust to adjustments for a range of potential confounders and was observed both in between-individual comparisons of all participants and within-individual comparisons using a casecrossover analysis. Furthermore, the finding was similar in the 2 independent data sets. Our findings regarding the number of tobacco outlets were less consistent, and we observed no association between changes in distance to tobacco outlets and the likelihood of smoking relapse in ex-smokers.

The main strengths of this longitudinal study included the use of high-resolution data, as practically all residential addresses and tobacco outlet addresses were successfully geocoded. These data were used in between-individual and withinindividual analyses. The advantages of the first approach include large sample size, longitudinal follow-up, and con- 


\begin{tabular}{|c|c|c|c|c|c|c|}
\hline \multirow[b]{2}{*}{ Cohort } & \multicolumn{3}{|c|}{ Model $1^{\mathrm{b}}$} & & \multicolumn{2}{|c|}{ Model $2^{b}$} \\
\hline & No. & OR $(95 \% \mathrm{CI})$ & $P$ Value & No. & OR $(95 \% \mathrm{Cl})$ & $P$ Value \\
\hline \multicolumn{7}{|l|}{ All } \\
\hline FPS & 1744 & $1.53(1.26-1.85)$ & $<.001$ & 1615 & $1.47(1.19-1.83)$ & $<.001$ \\
\hline HeSSup & 818 & $1.99(1.55-2.55)$ & $<.001$ & 648 & $1.76(1.33-2.35)$ & $<.001$ \\
\hline Pooled & & $1.69(1.45-1.97)$ & $<.001$ & & $1.57(1.32-1.86)$ & $<.001$ \\
\hline \multicolumn{7}{|l|}{ Men } \\
\hline FPS & 412 & $2.33(1.50-3.62)$ & $<.001$ & 387 & $2.44(1.50-3.97)$ & $<.001$ \\
\hline HeSSup & 353 & $2.17(1.44-3.26)$ & $<.001$ & 261 & $2.16(1.33-3.53)$ & .002 \\
\hline Pooled & & $2.24(1.66-3.03)$ & $<.001$ & & $2.30(1.63-3.24)$ & $<.001$ \\
\hline \multicolumn{7}{|l|}{ Women } \\
\hline FPS & 1332 & $1.36(1.10-1.69)$ & .004 & 1228 & $1.27(0.99-1.62)$ & .06 \\
\hline HeSSup & 465 & $1.88(1.38-2.58)$ & $<.001$ & 387 & $1.62(1.13-2.33)$ & .009 \\
\hline Pooled & & $1.51(1.26-1.81)$ & $<.001$ & & $1.37(1.12-1.68)$ & .002 \\
\hline \multicolumn{4}{|c|}{$\begin{array}{l}\text { Abbreviations: } \mathrm{Cl} \text {, confidence interval; FPS, the Finnish Public Sector study; } \\
\text { HeSSup, the Health and Social Support study; OR, odds ratio. } \\
\text { a Odds ratios }(95 \% \mathrm{Cl}) \text { for quitting smoking per } 500 \text {-m increase in distance to } \\
\text { the nearest tobacco outlet, derived from conditional (within-individual) }\end{array}$} & \multicolumn{3}{|c|}{$\begin{array}{l}\text { logistic regression analyses. Maximum value for distance is set at } 1000 \mathrm{~m} \\
\text { b Model } 1 \text { is adjusted for time and Model } 2 \text { additionally for time-variant } \\
\text { individual-level covariates: marital status, work status, chronic diseases, } \\
\text { worsening of financial situation. }\end{array}$} \\
\hline
\end{tabular}

trol for several potential confounders. However, it is more prone to bias compared with the case-crossover method because it does not control as rigorously for time-invariant individual characteristics of participants (both observed and unobserved), such as personality and genetic background. In addition, we were able to control for several major time-variant covariates, such as marital status, work status, chronic diseases, and recent death or severe illness in the family.

The results of this study support a causal association between decrease in residential availability of tobacco and quitting smoking, and they are consistent with several previous studies that were not based on within-individual analysis. For example, similar associations have previously been observed in studies of adults in the United States, ${ }^{7,11}$ Scotland, ${ }^{10}$ and in moderately or heavily smoking men in Finland, ${ }^{14}$ whereas in an English study no association was observed between quitting and availability of tobacco close to residence. ${ }^{12}$ In agreement, we did not observe associations for changes in tobacco availability and smoking relapse. This suggests that other factors, such as presence of other smokers, ${ }^{25}$ may have stronger effect on relapsing than availability of tobacco near home.

There are at least 2 plausible mechanisms for reasons why reduced residential availability of tobacco may decrease smoking. First, having a tobacco outlet closer to home decreases the time and travel costs related to purchasing tobacco. ${ }^{26,27}$ Second, higher density of tobacco outlets may promote smoking by increasing environmental cues to smoke. ${ }^{5,28}$ However, the latter mechanism is less likely in our study as in Finland advertising of tobacco, including point-of-sale advertising, has been prohibited since 1976 and the display of tobacco products at point-of-sale was banned in January $2012 .^{16}$

Previous research suggests that people in socioeconomically deprived neighborhoods smoke more than those in affluent neighborhoods, independently of individual-level socioeconomic status. ${ }^{29-31}$ Furthermore, some findings support a link between increase in neighborhood socioeconomic dis- advantage due to change in residence and increased smoking. ${ }^{24}$ In our data, median road distance to the nearest tobacco outlet was $350 \mathrm{~m}$ in neighborhoods with above median social disadvantage $\mathrm{e}^{32}$ and $720 \mathrm{~m}$ in the least disadvantaged areas. High availability of tobacco may be an explanation for increased likelihood of smoking among people living in disadvantaged areas. ${ }^{23,29,33}$

The study also had its limitations. Including no biological measures to validate self-reported smoking may have led to some misclassification of tobacco use, although previous studies suggest that self-report is a reasonably valid method to measure smoking behaviors among Finns. ${ }^{34}$ Although response rate for FPS was good, a 63\% response rate for the 2003 HeSSup participants may have led to nonresponse bias. We were able to measure availability of tobacco only in residential environments ${ }^{35}$ and thus could not include access to tobacco at other activity locations, such as workplaces. The case-crossover design best applies in studies where the exposure is intermittent and affects risk immediately, and the outcome is abrupt. ${ }^{21}$ Distance to tobacco outlet fits with this design as this exposure varies over time; smoking is similarly a suitable outcome with a distinct onset. However, we were not able to identify the exact time of quitting; this could have resulted in some imprecision in the time at each exposure and outcome category but is an unlikely source of systematic bias to our results.

Data on tobacco outlet locations were available only from 2010 onwards, which may have caused some measurement error regarding distance to the nearest tobacco outlet at baseline in the HeSSup cohort. However, our sensitivity analysis using availability of alcohol in 2004 and 2010 as proxy measure for availability of tobacco suggests that a major bias owing to baseline discrepancy was unlikely. Moreover, findings regarding quitting were similar in HeSSup and FPS, a cohort with no discrepancy in baseline measurements, further increasing confidence to the findings. 
The generalizability of our findings should be interpreted cautiously. Although the participants were drawn from a variety of geographical areas and were from 2 different cohorts (a population sample and an occupational cohort), all the data were from Finland, a country which has strict antismoking policies. This may limit the generalizability of the findings to societies with more relaxed regulations concerning the availability of tobacco. In addition, FPS is an occupational cohort which limits the generalization of the results from that specific cohort to the general population. Lastly, we were not able to examine whether availability of tobacco affected the risk of initiating smoking. Further studies focusing on neversmoking adolescents are needed to address this question.

Our findings have important policy implications. Finland has a goal of a tobacco-free society as a legislative objective. ${ }^{36}$ Despite this, the prevalence of smoking has remained at $16 \%,{ }^{16}$ suggesting that further measures are needed to reduce smoking. ${ }^{4,27,37}$ There are several potential ways to reduce the number of tobacco outlets, such as limiting tobacco retail licenses based on the existing density of tobacco outlets or prox- imity to schools or hospitals ${ }^{4,5,27,37,38}$ or offering incentives for retailers to stop selling tobacco products. ${ }^{4,5,39}$ Research conducted in New Zealand ${ }^{40}$ and the United States, ${ }^{41}$ for example, suggest that actions to reduce the number of tobacco outlets would have public support. Indeed, CVS, among some other drug-outlet chains in the United States, have stopped selling cigarettes. ${ }^{42,43}$

\section{Conclusions}

To the best of our knowledge, this is the first study to examine the impact of change in access to tobacco on smoking behaviors in 2 large independent data sets using betweenindividual and within-individual comparisons. We found robust evidence suggesting that among Finnish adults who smoked, increase in the distance from home to a tobacco outlet increased the odds of quitting smoking. Among exsmokers, however, change in distance to the nearest tobacco outlet was not associated with smoking behaviors.

\section{ARTICLE INFORMATION}

Accepted for Publication: May 27, 2016.

Published Online: August 15, 2016.

doi:10.1001/jamainternmed.2016.4535

Author Affiliations: Department of Public Health, University of Turku, Turku, Finland (Pulakka, Stenholm, Vahtera); Finnish Institute of Occupational Health, Helsinki, Finland (Halonen, Pentti, Kivimäki); Department of Social and Behavioral Sciences, Harvard T. H. Chan School of Public Health, Boston, Massachusetts (Kawachi); School of Health Sciences, University of Tampere, Tampere, Finland (Stenholm); Institute of Behavioural Sciences, University of Helsinki, Helsinki, Finland (Jokela); Department of Geography and Geology, University of Turku, Turku, Finland (Kaate); Clinicum, Faculty of Medicine, University of Helsinki, Helsinki, Finland (Koskenvuo Kivimäki); Turku University Hospital, Turku, Finland (Vahtera); Department of Epidemiology and Public Health, University College London Medical School, London, England (Kivimäki).

Author Contributions: Drs Vahtera and Kivimäki had full access to all the data in the study and take responsibility for the integrity of the data and the accuracy of the data analysis. Drs Vahtera and Kivimäki are cosenior authors.

Concept and design: Pulakka, Halonen, Pentti, Koskenvuo, Vahtera, Kivimäki.

Acquisition, analysis, or interpretation of data: All Authors.

Drafting of the manuscript: Pulakka, Pentti, Stenholm, Kivimäki.

Critical revision of the manuscript for important intellectual content: All authors.

Statistical analysis: Pulakka, Pentti, Jokela.

Obtaining funding: Stenholm, Koskenvuo, Vahtera, Kivimäki.

Administrative, technical, or material support:

Kaate, Koskenvuo.

Study supervision: Halonen, Koskenvuo, Vahtera, Kivimäki.

Conflict of Interest Disclosures: None reported.
Funding/Support: This study was supported by Academy of Finland (grants 26080431 and 26080432 to Dr Stenholm), the UK Medical Research Council (grant No. K013351 to Dr Kivimäki); Economic and Social Research Council (to Dr Kivimäki); and NordForsk, the Nordic Programme for Health and Welfare (grant No. 75021 to Dr Kivimäki). The HeSSup study was supported by the Social Insurance Institution of Finland.

Role of the Funder/Sponsor: The funders had no role in the design and conduct of the study; collection, management, analysis, and interpretation of the data; preparation, review, or approval of the manuscript; and decision to submit the manuscript for publication.

Additional Contributions: Ville Aalto, MSc, from the Finnish Institute of Occupational Health, Turku, Finland helped with the statistical analysis and received no additional compensation for his contributions.

\section{REFERENCES}

1. Ng M, Freeman MK, Fleming TD, et al. Smoking prevalence and cigarette consumption in 187 countries, 1980-2012. JAMA. 2014;311(2):183-192.

2. Forouzanfar MH, Alexander L, Anderson HR, et al; GBD 2013 Risk Factors Collaborators. Global, regional, and national comparative risk assessment of 79 behavioural, environmental and occupational, and metabolic risks or clusters of risks in 188 countries, 1990-2013: a systematic analysis for the Global Burden of Disease Study 2013. Lancet. 2015; 386(10010):2287-2323.

3. Holford TR, Meza R, Warner KE, et al. Tobacco control and the reduction in smoking-related premature deaths in the United States, 1964-2012. JAMA. 2014;311(2):164-171.

4. Cohen JE, Anglin L. Outlet density: a new frontier for tobacco control. Addiction. 2009;104 (1):2-3.

5. Henriksen L. Comprehensive tobacco marketing restrictions: promotion, packaging, price and place. Tob Control. 2012;21(2):147-153.
6. Chuang YC, Cubbin C, Ahn D, Winkleby MA Effects of neighbourhood socioeconomic status and convenience store concentration on individual level smoking. J Epidemiol Community Health. 2005;59(7):568-573.

7. Reid RJ, Peterson NA, Lowe JB, Hughey J. Tobacco outlet density and smoking prevalence: Does racial concentration matter? Drugs Educ Prev Policy. 2005;12(3):233-238.

8. Novak SP, Reardon SF, Raudenbush SW, Buka SL. Retail tobacco outlet density and youth cigarette smoking: a propensity-modeling approach. Am J Public Health. 2006;96(4):670-676.

9. Lipperman-Kreda S, Grube JW, Friend KB. Local tobacco policy and tobacco outlet density: associations with youth smoking. J Adolesc Health. 2012;50(6):547-552.

10. Pearce J, Rind E, Shortt N, Tisch C, Mitchell R. Tobacco Retail Environments and Social Inequalities in Individual-Level Smoking and Cessation Among Scottish Adults. Nicotine Tob Res. 2016;18(2):138-146.

11. Reitzel LR, Cromley EK, Li Y, et al. The effect of tobacco outlet density and proximity on smoking cessation. Am J Public Health. 2011;101(2):315-320.

12. Han T, Alexander M, Niggebrugge $A$, Hollands GJ, Marteau TM. Impact of tobacco outlet density and proximity on smoking cessation: a longitudinal observational study in two English cities. Health Place. 2014;27:45-50.

13. Cantrell J, Anesetti-Rothermel A, Pearson JL, Xiao H, Vallone D, Kirchner TR. The impact of the tobacco retail outlet environment on adult cessation and differences by neighborhood poverty. Addiction. 2015;110(1):152-161.

14. Halonen Jl, Kivimäki M, Kouvonen $A$, et al. Proximity to a tobacco store and smoking cessation: a cohort study. Tob Control. 2014;23(2): 146-151.

15. Suominen S, Koskenvuo K, Sillanmäki L, et al. Non-response in a nationwide follow-up postal survey in Finland: a register-based mortality analysis of respondents and non-respondents of 
the Health and Social Support (HeSSup) Study. BMJ Open. 2012;2(2):e000657.

16. National Institute for Health and Welfare. Tobacco statistics 2013. http://www.julkari.fi /handle/10024/116822. Accessed March 14, 2016.

17. Finnish Transport Agency. Digiroad. A National Road and Street Database. http://www

liikennevirasto.fi/web/en/open-data/services /digiroad\#.VzmuE3peFvt. Accessed May 16, 2016.

18. Halonen Jl, Kivimäki M, Virtanen M, et al. Living in proximity of a bar and risky alcohol behaviours: a longitudinal study. Addiction. 2013;108(2):320-328.

19. Bednarek M, Gorecka D, Wielgomas J, et al. Smokers with airway obstruction are more likely to quit smoking. Thorax. 2006;61(10):869-873.

20. Coulter R, Scott J. What motivates residential mobility? re-examining self-reported reasons for desiring and making residential moves. Popul Space Place. 2015;21(4):354-371.

21. Maclure M, Mittleman MA. Should we use a case-crossover design? Annu Rev Public Health. 2000;21(1):193-221.

22. Allison P. Fixed effects regression methods in SAS. http://www2.sas.com/proceedings/sugi31 /184-31.pdf. Accessed February 2, 2016

23. Jokela M. Are neighborhood health associations causal? A 10-year prospective cohort study with repeated measurements. Am J Epidemiol. 2014;180(8):776-784.

24. Halonen JI, Pulakka A, Stenholm S, et al. Effect of a change in neighbourhood disadvantage on smoking behaviors in adults: a longitudinal within-individual study. Epidemiology. In press.

25. Zhou X, Nonnemaker J, Sherrill B, Gilsenan AW, Coste F, West R. Attempts to quit smoking and relapse: factors associated with success or failure from the ATTEMPT cohort study. Addict Behav. 2009;34(4):365-373.
26. Schneider JE, Reid RJ, Peterson NA, Lowe JB, Hughey J. Tobacco outlet density and

demographics at the tract level of analysis in lowa: implications for environmentally based prevention initiatives. Prev Sci. 2005;6(4):319-325.

27. Pearson AL, van der Deen FS, Wilson N, Cobiac $\mathrm{L}$, Blakely T. Theoretical impacts of a range of major tobacco retail outlet reduction interventions: modelling results in a country with a smoke-free nation goal. Tob Control. 2015;24(e1):e32-e38.

28. Wakefield M, Germain D, Henriksen L. The effect of retail cigarette pack displays on impulse purchase. Addiction. 2008;103(2):322-328.

29. Ivory VC, Blakely T, Richardson K, Thomson G, Carter K. Do changes in neighborhood and household levels of smoking and deprivation result in changes in individual smoking behavior? A large-scale longitudinal study of New Zealand adults. Am J Epidemiol. 2015;182(5):431-440. 30. Stimpson JP, Ju H, Raji MA, Eschbach K. Neighborhood deprivation and health risk behaviors in NHANES III. Am J Health Behav. 2007; 31(2):215-222.

31. Karriker-Jaffe KJ. Neighborhood socioeconomic status and substance use by U.S. adults. Drug Alcohol Depend. 2013;133(1):212-221.

32. Halonen JI, Stenholm S, Pentti J, et al. Childhood Psychosocial Adversity and Adult Neighborhood Disadvantage as Predictors of Cardiovascular Disease: A Cohort Study. Circulation. 2015;132(5):371-379.

33. Giskes K, van Lenthe FJ, Turrell G, Brug J, Mackenbach JP. Smokers living in deprived areas are less likely to quit: a longitudinal follow-up. Tob Control. 2006;15(6):485-488.

34. Vartiainen E, Seppälä T, Lillsunde P, Puska P. Validation of self reported smoking by serum cotinine measurement in a community-based study. J Epidemiol Community Health. 2002;56(3):167-170.
35. Shareck M, Kestens Y, Vallée J, Datta G, Frohlich $\mathrm{KL}$. The added value of accounting for activity space when examining the association between tobacco retailer availability and smoking among young adults. [published online June 1, 2015]. Tob Control. 2016;25(4):406-412. doi:10.1136 /tobaccocontrol-2014-052194.

36. Ministry of Social Affairs and Health. Roadmap to a tobacco-free Finland. Action plan on tobacco control. Publications of the Ministry of Social Affairs and Health. 2014;12. https://www.julkari.fi /bitstream/handle/10024/116794/URN_ISBN_978 -952-00-3513-6.pdf?sequence $=1$. Accessed July 6 , 2016.

37. Chapman S, Freeman B. Regulating the tobacco retail environment: beyond reducing sales to minors. Tob Control. 2009;18(6):496-501.

38. Myers AE, Hall MG, Isgett LF, RibisI KM. A comparison of three policy approaches for tobacco retailer reduction. Prev Med. 2015;74:67-73.

39. Paynter J, Glover M, Bullen C, Sonia D. An intervention to reduce the number of convenience stores selling tobacco: feasibility study. Tob Control. 2016;25(3):319-324.

40. Whyte G, Gendall P, Hoek J. Advancing the retail endgame: public perceptions of retail policy interventions. Tob Control. 2014;23(2):160-166.

41. Farley SM, Coady MH, Mandel-Ricci J, et al. Public opinions on tax and retail-based tobacco control strategies. Tob Control. 2015;24(e1):e10-e13.

42. Brennan TASS, Schroeder SA. Ending sales of tobacco products in pharmacies. JAMA. 2014;311 (11):1105-1106.

43. Krumme AA, Choudhry NK, Shrank WH, et al. Cigarette purchases at pharmacies by patients at high risk of smoking-related illness. JAMA Intern Med. 2014;174(12):2031-2032. 